\section{Separation and Identification of Aromatic Amines by Two-Dimensional Thin-Layer Chromatography of Charge-Transfer Complexes}

Trennung und Identifizierung aromatischer Amine durch zweidimensionale Dünnschicht-Chromatographie von Charge-Transfer-Komplexen

Trenn. von Aminen, aromatische; Chromatographie, Dünnschicht; Charge-Transfer-Komplexe

J. P. Sharma and Sushma Ahuja

Dept. of Chemistry, University Allahabad, India

Received March 9, 1973; revised May 29, 1973

Aromatic amines form weak association complexes with aromatic nitro compounds and the association constants of the complexes formed with a given acceptor are usually different depending upon the donor strengths of amines. When m-dinitrobenzene is impregnated in the thin-layers made of silica gel and the aromatic amines chromatographed on these layers, good separation is achieved. The $R_{\mathbf{f}}$-values of the systems have been given in few different solvents, and the conditions for the separation of solid and liquid amines have been specified.

\section{Experimental}

Solvents. a) n-heptane saturated with liquor ammonia, b) chloroform saturated with water, c) carbon tetrachloride saturated with water.

Preparation of Plates. Equal quantities of silica gel G and m-dinitrobenzene were intimately mixed. A slurry was prepared by mixing $5 \mathrm{~g}$ of the above mixture with $12.5 \mathrm{ml}$ of distilled water. This slurry was sufficient for making five plates of $5 \times 20 \mathrm{~cm}$ size. The slurry was spread on the plates and thin-layers of $300 \mu \mathrm{m}$ thickness were prepared and dried in air at room temperature for 1.5 to $2 \mathrm{~h}$.

Procedure. About $0.25 \mu \mathrm{l}$ of each test solution was spotted with a micropipette on the plates at a distance of about $1.5 \mathrm{~cm}$ from the top. The reference spots were applied on both sides of the central spot at the same distance from the top. The spot was air-dried for $5-8 \mathrm{~min}$. The plates were
Table 1. $R_{f}-$ Values of aromatic amines with $n$-heptane, chloroform and carbon tetrachloride

\begin{tabular}{llll}
\hline S.No. Amines & \multicolumn{4}{l}{$\mathrm{R}_{\mathrm{f} \text {-values a }}$} \\
\cline { 2 - 4 } & (a) & (b) & (c) \\
\hline Liquid amines & & & \\
1. Aniline & & & \\
2. m-Toluidine & 0.096 & - & 0.37 \\
3. o-Toluidine & 0.17 & - & - \\
4. N-Methyl aniline & 0.19 & - & - \\
5. N,N-Dimethyl aniline & 0.26 & - & 0.73 \\
Solid amines & 0.46 & - & 0.89 \\
6. p-Aminobenzoic acid & & & \\
7. Benzidine & - & 0.03 & - \\
8. o-Aminobenzoic acid & - & 0.09 & - \\
9. $\alpha$-Naphthylamine & - & 0.12 & - \\
10. $\beta$-Naphthylamine & - & 0.30 & 0.24 \\
11. p-Toluidine & - & 0.30 & 0.17 \\
\hline
\end{tabular}

$\mathrm{a}-\mathrm{c}=$ Solvents, see text.

a All the $\mathbf{R}_{\mathrm{f}}$-values are average of three to four runs.

inserted in the tanks which had already been saturated with solvent vapour for $10 \mathrm{~min}$.

The plates were developed for $30-35 \mathrm{~min}$ except in the case of carbon tetrachloride where the development time was 75-80 min. After the development, the solvent-front was marked and the solvent was allowed to evaporate at room temperature after marking the solvent front. The spots were self-revealing. The amines were identified with the help of reference spots having same area and having travelled the same distance. The corresponding $R_{\mathrm{p} \text {-values were calcu- }}$ lated.

After standardising the procedure separately for liquid and solid amines using n-heptane (saturated with ammonia) and chloroform (saturated with water) respectively, the mixture of liquid and solid amines could be separated on the same plate. First the plate was developed with solvent a) when only liquid amines moved. After evaporating the solvent at room temperature, the plate was again developed in a perpendicular direction with the solvent b) when solid amines separated.

Results of separations are recorded in Table 1.

Dr. J. P. Sharma

Dept. of Chemistry

University of Allahabad

Allahabad, India 